\title{
ESDA2010-प००००
}

\section{ON MEASURING DYNAMIC PROPERTIES OF DAMPING MATERIALS USING OBERST BEAM METHOD}

\author{
Hasan Koruk* \\ Department of Mechanical Engineering \\ Vibration and Acoustics Laboratory \\ Istanbul Technical University, Istanbul, Turkey \\ E-mail: koruk@itu.edu.tr
}

\author{
Kenan Y. Sanliturk \\ Department of Mechanical Engineering \\ Vibration and Acoustics Laboratory \\ Istanbul Technical University, Istanbul, Turkey \\ E-mail: sanliturk@itu.edu.tr
}

\begin{abstract}
The Oberst Beam Method is widely used for the measurement of the mechanical properties of damping materials. This method is a classical method based on a multilayer cantilever beam which consists of a base beam and one or two layers of other materials. The base beam is almost always made of a lightly damped material such as steel and aluminum.

If the Oberst Beam Method (OBM) is to be used, it is essential to establish a very accurate measurement methodology. In this respect, the response and the excitation sensors in the Oberst test rig are generally non-contact type. Although the drawbacks of contacting type of transducers are eliminated by this way, there are other critical issues when OBM is used. It is therefore essential to be aware of the parameters that might adversely affect the measured data and also to avoid them as much as possible. Consequently, all the parameters affecting the result need to be optimized in order to obtain the material properties with high accuracy. Although the OBM is referenced in some standards and widely used in scientific studies, detailed information in the literature on how to perform a successful Oberst Beam experiment is very limited. This is the main subject this paper aims to address. In this paper, after setting up the Oberst test rig the effects of various parameters on measured data using an Oberst test rig are examined in an attempt to improve the accuracy of the estimated material properties. Then repeatability measurements are performed and the main parameters affecting the quality of the measured data are identified. After that, extensive tests are performed so as to determine the effect of the amplitude of the excitation force, adverse effects of electromagnetic excitation and the effects of length of the test specimen. Furthermore, it is
\end{abstract}

found that the small differences between individual samples may also affect the results significantly. Finally, some suggestions are given to the potential users of the OBM so as to avoid undesirable effects of certain parameters during such measurements.

\section{INTRODUCTION}

Damping in composite materials is an important parameter affecting the dynamic behavior of structures, controlling the resonant and near-resonant vibration levels. For the solution of variety of noise and vibration problems, especially those associated with vibrations of structures made of sheet metal, surface damping treatments are often used. Such treatments can easily be applied to existing structures and provide high damping capability over wide temperature and frequency ranges.

Based on the rapid development in the automotive, aircraft industry, etc. there have been many experimental and theoretical studies on composite damped structures subjected to dynamic loading [1]. The first important work on measurements and calculations of loss factor of composite structures is published by Oberst in 1952 [2]. He derived a set of equations for free layer damping treatment. Although some other associated works were done by Ross et al. [3], Gross [4], Edward [5] and DiTaranto [6], mainly the driven equations by Oberst are used in Oberst Beam Method (OBM).

OBM is the classical method for the characterization of damping materials based on a multilayer cantilever beam which consists of a base beam and one or two layers of other materials [7]. The base beam is almost always made of a lightly damped material such as steel and aluminum. This method is useful in testing materials such as metals, enamels, ceramics, rubbers,

*Address all correspondence to this author. 
plastics, reinforced epoxy matrices and woods. The mentioned multilayer cantilever beam is given in Fig. 1. The root of the beam is wedged into a heavy and stiff clamping system.

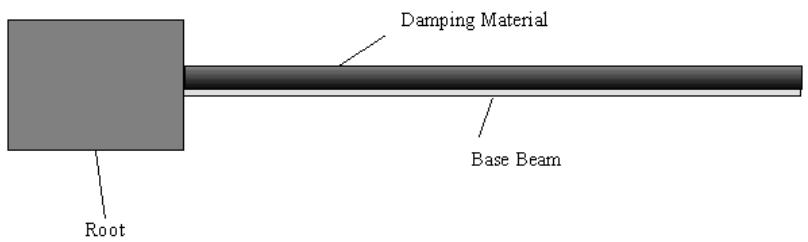

Figure 1. CANTILEVER BEAM USED IN THE OBERST BEAM METHOD.

Oberst beam method is based on performing some Frequency Response Function (FRF) measurements on both the bare and damped beams. First of all, the FRF measured on the bare beam is analyzed to determine natural frequencies within the frequency range of interest. Then, measured FRF on the damped beam is analyzed in order to determine the natural frequencies and corresponding modal loss factors of the composite beam. Using the determined natural frequencies of the bare beam, and the natural frequencies and loss factors of the damped beam, Young's modulus and damping level (loss factor) of the damping material are identified at frequencies corresponding to the vibration modes of the damped (composite) beam.

The use of contacting transducers is not recommended in OBM. The use of contacting transducers adds damping and mass to the beam as a result of the attachments of the excitation and response sensors and this significantly reduces the quality of the results in Oberst beam method [8].

- Attaching a shaker is not recommended as an exciter as this will lead to adding damping, mass and stiffness to the Oberst beam. Therefore, electromagnetic non contacting transducers should be used. If aluminum is used as the material of base beam, it is necessary to glue a small piece of magnetic material for providing magnetic excitation. However, the effects of mass and damping due to this piece must also be taken into account.

- Non contacting response transducer is preferred. However, in the case of measurement of the response of the beam with an accelerometer, this will results in additional damping and mass to the beam, and again their adverse effects must be taken into account. Although the clamping conditions of the beam are usually satisfactory, problems may occur in the case of misalignment, insufficient clamping force and bad machining of the root.

Even though the drawbacks of contacting type of transducers can be eliminated by using non contacting response and exciting transducers, there are still other critical issues when Oberst Beam Method (OBM) is used in practice. Therefore it is essential to be aware of the parameters that might adversely affect the measured data and also to avoid them as much as possible. Consequently, all the parameters affecting the result need to be optimized in order to obtain the material properties with high accuracy. Although the OBM is referenced in some standards [7 and 9] and it is widely used in many scientific studies [10-14], detailed information in the literature on how to perform a successful Oberst Beam experiment is very limited. This is precisely the main subject this paper is addressing here. In this paper, the effects of various parameters on measured data using an Oberst test rig are examined in an attempt to improve the accuracy of the estimated material properties. Repeatability measurements are performed and the main parameters affecting the quality of the measured data are determined on the Oberst test rig set up. Then, a lot of tests are performed in order to determine the effect of the amplitude of the excitation force, adverse effects of electromagnetic excitation and the effects of the lengths of the individual test specimens. Furthermore, it is noted that small differences between individual samples may also affect the results significantly. Finally, some suggestions are given to the potential users of the OBM so as to avoid undesirable effects of certain parameters during such measurements.

\section{TEST RIG AND MEASUREMENT PARAMETERS}

The Oberst test rig consists of an exciter, a response sensor and an Oberst beam mounted on a test stand. The measurement system used in this paper is given in Fig 2. Also, a typical process for obtaining a FRF using Oberst test rig is illustrated in Fig. 3.

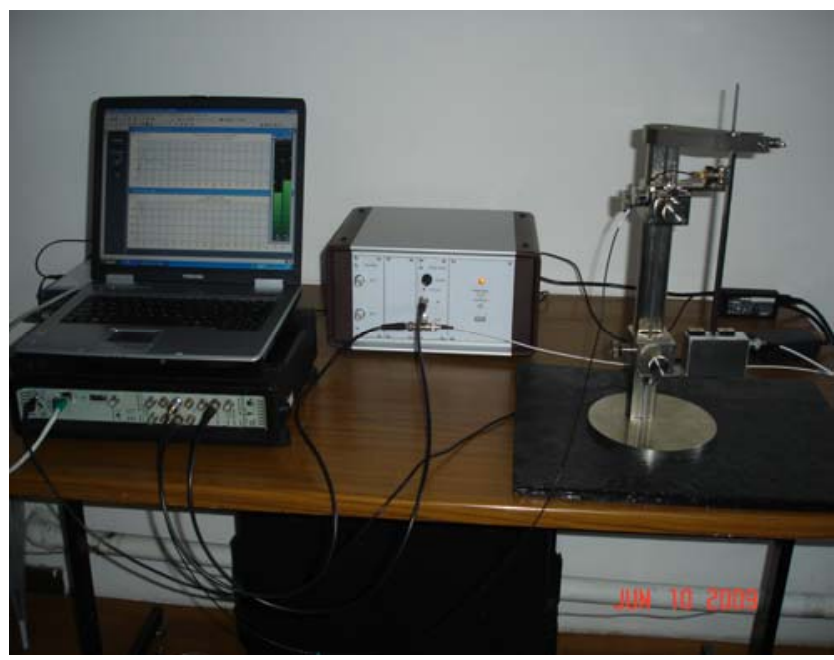

Figure 2. MEASUREMENT SYSTEM.

The frequency range of interest is set to 2-2000 Hz, which is also compatible with the frequency range of the sensors used. Hanning windowing is applied to both response and excitation signals. Also appropriate frequency resolution is selected. 


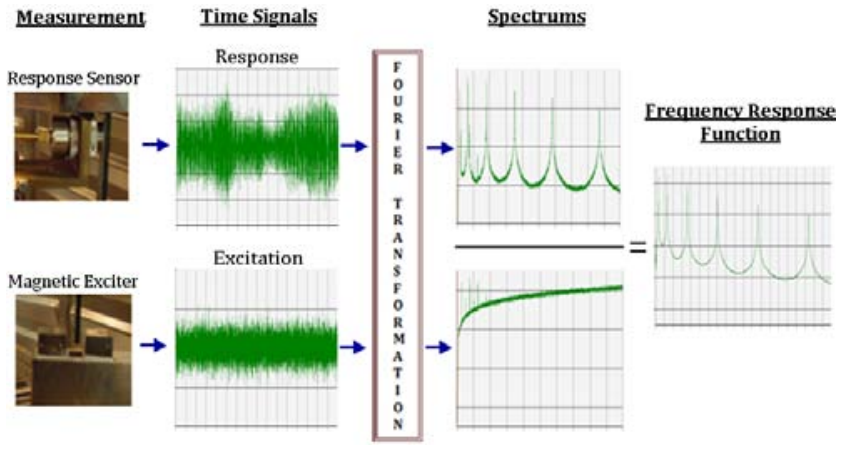

Figure 3. ILLUSTRATION OF MEASUREMENT OF FRFs USING OBERST TEST RIG.

Two different types of excitations, namely sine sweep and random, are applied and corresponding FRFs in the case of beam length of $220 \mathrm{~mm}$ are obtained and presented in Fig. 4. As can be seen, almost identical results are obtained in both cases. As a result, it is decided to use mainly random type of excitation for the rest of the results presented here.
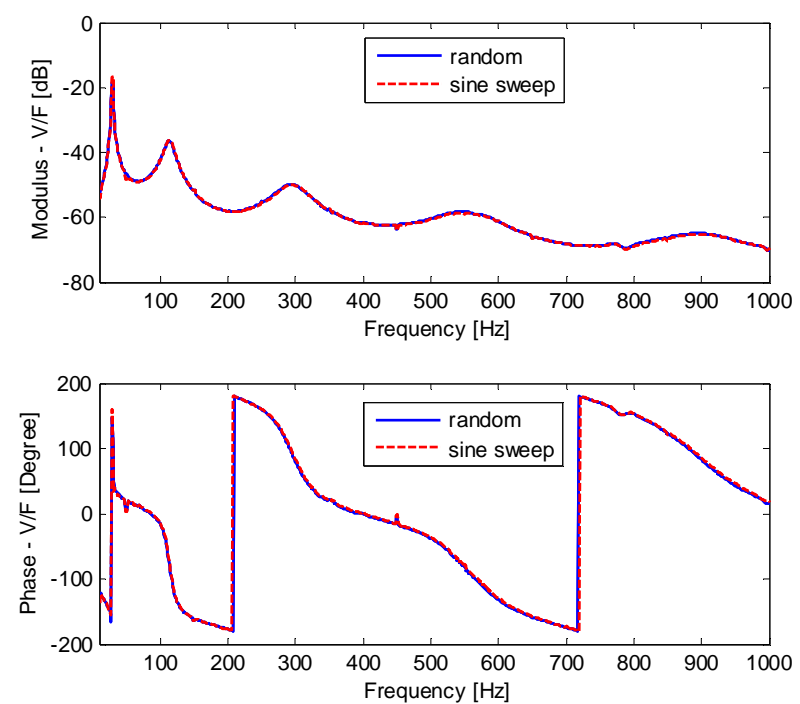

Figure 4. FRFs FOR RANDOM AND SINE SWEEP EXCITATIONS.

To minimize the noise level, a number of averages should be used although large number of averaging leads to excessive time consuming. The FRFs measured on a bare beam for 5, 10 and 50 averages are given in Fig. 5. For an appropriate result, 10 or more averaging seems to be appropriate. In this work FRF measurements are done using about 50 averages in order to minimize the noise level.

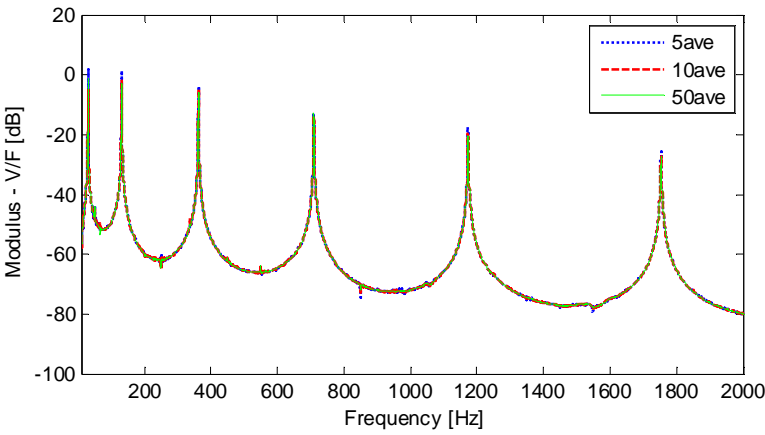

Figure 5. FRFs FOR VARIOUS NUMBERS OF AVERAGES 10 and 50 AVERAGES).

\section{IMPROVING THE MEASUREMENT QUALITY}

In order to optimize the measurement parameters that lead to higher accuracy of the estimated material properties, many FRFs are measured using various samples under various conditions. Comparisons are made in terms of measured FRFs and sometimes in terms of natural frequencies and material properties. Natural frequencies and loss factors are determined using measured FRFs by utilizing the Line-Fit method [15]. Material properties are calculated according to the procedure described in ASTM E-756 standard [7] using experimentally determined natural frequencies and loss factors of the bare and damped beams.

\subsection{Repeatability Tests}

Repeatability must be guaranteed in Oberst Beam Method (OBM) because at least two FRF measurements (one for the bare beam and the other for the damped composite beam) are needed for the determination of material properties. This requires the need for satisfying repeatable boundary, excitation and response conditions. The setup for data acquisition must also be repeatable. For various schemes, repeatability tests are performed and outlined below.

To ensure that measurements are repeatable and that the system has no problems, three set of FRF measurements are performed on the same sample (bare beam) without changing any conditions and the results with 50 averages are given in Fig. 6.

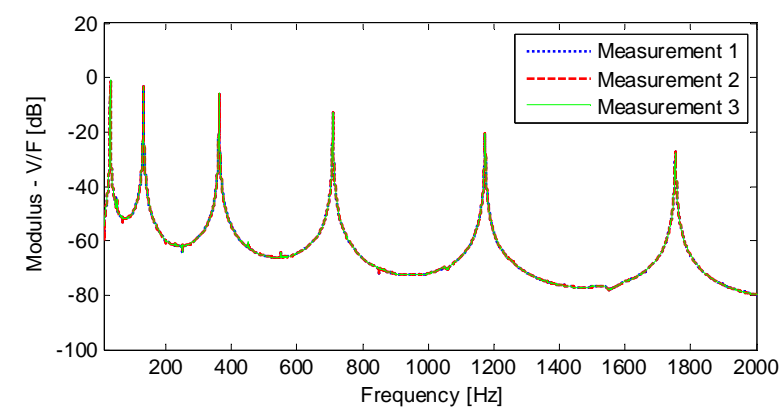

Figure 6. THREE SET OF FRF MEASUREMENTS PERFORMED ON THE SAME (BARE) SAMPLE. 
As seen in Fig. 6, repeated measurements are almost the same, implying that the measurement system is functioning properly. Also, a set of FRF measurements that are performed on a damped beam sample $(\mathrm{L}=220 \mathrm{~mm})$ are given in Fig. 7. Once again, almost identical results are obtained in all three cases.
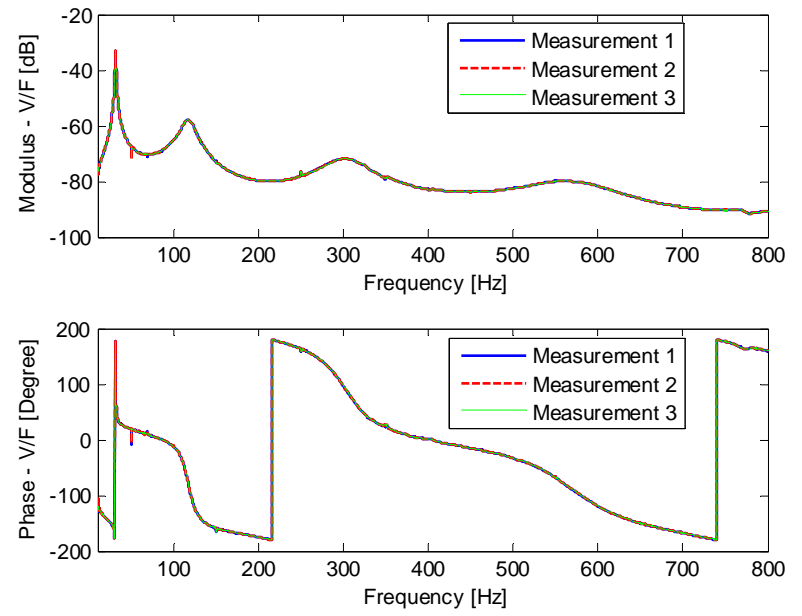

Figure 7. THREE FRF MEASUREMENTS ON THE SAME SAMPLE (DAMPED BEAM).

As stated before at least two FRF measurements (one for bare beam and the other for damped beam) are needed even for determining material properties of a damping material. This requires that mounting conditions in two different measurements should be as identical as possible. To check whether the sample is clamped to the mounting fixture with the same length and clamping conditions, the same sample is fixed to the Oberst stand, measurements are made, and it is removed and then refitted and measurements are done again. This process is repeated a few times to check whether the repeatable clamping conditions and the same beam length will be achieved every time. It is found that the use of a kind of "stopper" is very useful for assuring that the beam will have almost the same free length every time. This approach is utilized and very good repeatability measurements are obtained as illustrated in Fig. 8.

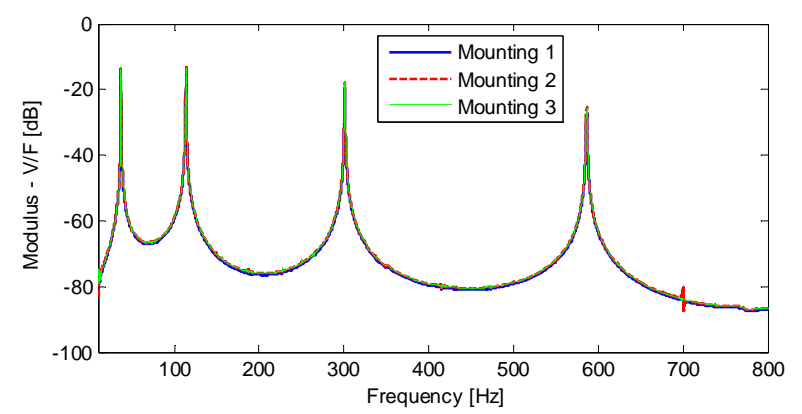

Figure 8. FRF MEASUREMENTS FOR VARIOUS MOUNTING CHANGES.
Natural frequencies obtained from three measurements given in Fig. 8 are listed in Table 1. As seen, the results are almost the same and the error due to repeatability issue can be considered negligible. This confirms that there is no repeatability problem associated with mounting the beams to the fixture.

Table 1. REPEATABILITY TESTS: IDENTICAL NATURAL FREQUENCIES [in $\mathrm{Hz}$ ] USING REPEATED MOUNTING CASES.

\begin{tabular}{|l|c|c|c|}
\hline & 1st Mea. & 2nd Mea. & 3rd Mea. \\
\hline Mode 2 & 113,5 & 113,5 & 113,5 \\
\hline Mode 3 & 301,0 & 300,9 & 301,0 \\
\hline Mode 4 & 586,4 & 586,1 & 586,4 \\
\hline
\end{tabular}

Also, the repeatability for different bare beams is investigated by measuring FRFs for some beam samples (see Fig. 9). Identified natural frequencies and the maximum differences in natural frequencies for three different beam samples are given in Table 2. Again, the results are almost the same.

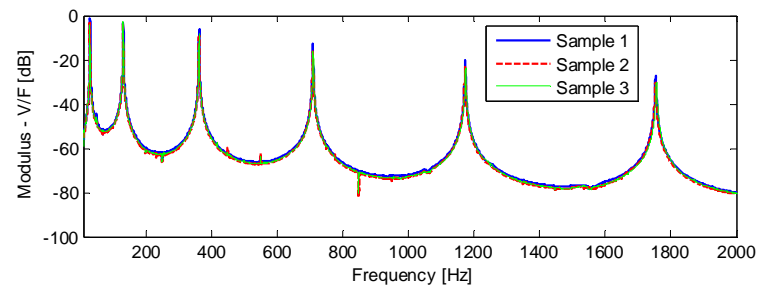

Figure 9. FRFs MEASURED ON THREE DIFFERENT BARE SAMPLES.

Table 2. MEASURED NATURAL FREQUENCIES [in Hz] FOR DIFFERENT BARE BEAM SAMPLES.

\begin{tabular}{|l|c|c|c|c|c|}
\hline & Mode 2 & Mode 3 & Mode 4 & Mode 5 & Mode 6 \\
\hline Sample 1 & 131.25 & 362.50 & 709.40 & 1173.10 & 1753.70 \\
\hline Sample 2 & 130.95 & 362.20 & 709.05 & 1172.50 & 1753.10 \\
\hline Sample 3 & 131.25 & 361.90 & 708.45 & 1172.05 & 1752.60 \\
\hline $\begin{array}{l}\text { Difference } \\
\text { in Freq. [\%] }\end{array}$ & 0.23 & 0.17 & 0.13 & 0.09 & 0.06 \\
\hline
\end{tabular}

Also, the repeatability for different damped beams is investigated by measuring FRFs for some composite samples (see Fig. 10). Again, the results are almost identical to each other.

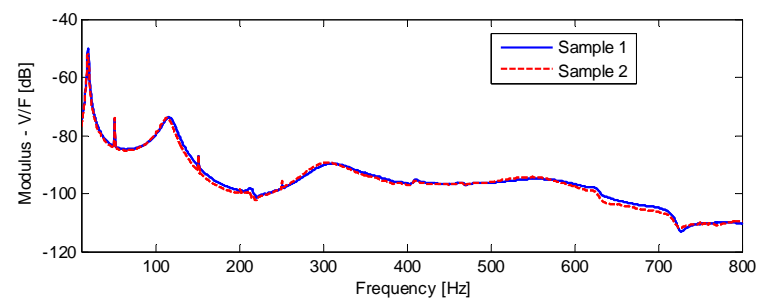

Figure 10. FRFs MEASURED ON TWO SAMPLES OF A DAMPING MATERIAL. 


\subsection{Effects of Amplitude of Excitation Force}

There is a range of excitation level that can be applied by the noncontact exciter. It is essential that the excitation must be strong enough to obtain high signal to noise ratio. However, it is also necessary not to exceed certain level in order to remain within the linear range. This is assured after some trial tests so as to establish a range that is appropriate for reliable measurements. Some FRFs are measured using forcing levels within this range, identified here as low, medium and high and results are compared in Fig. 11.

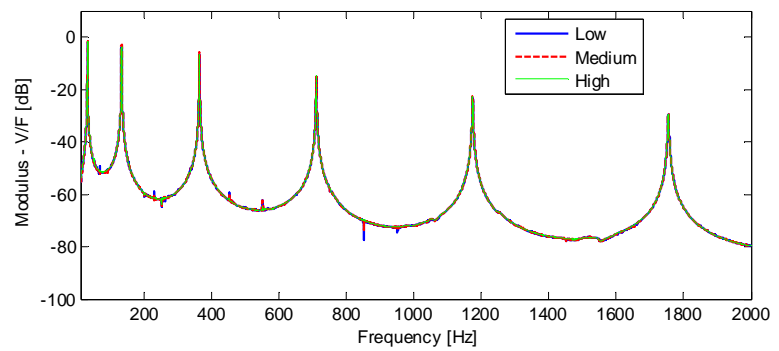

Figure 11. FRFs MEASURED FOR VARIOUS FORCE LEVELS (LOW, MEDIUM AND HIGH).

As can be seen in Fig. 11, almost the same results can be obtained again if the initial trial tests are performed in order to identify appropriate forcing levels. Identified natural frequencies using the FRFs in Fig.11 under three different forcing levels are given in Table 3 for the first three modes. As seen, the differences between the natural frequencies obtained at different forcing levels are quite small, hence can be neglected.

Table 3. THE NATURAL FREQUENCIES [in Hz] FOR VARIOUS EXCITATION FORCE LEVELS.

\begin{tabular}{|l|r|c|c|}
\hline & \multicolumn{1}{|c|}{ High } & Medium & Low \\
\hline Mode 2 & 113,3 & 113,5 & 113,5 \\
\hline Mode 3 & 301,0 & 301,2 & 301,0 \\
\hline Mode 4 & 586,4 & 586,4 & 586,4 \\
\hline
\end{tabular}

It is worth restating that appropriate forcing levels should be determined before making final measurements and this depends on the Oberst testing system used. However, it is almost certain that this process requires some initial trial measurements.

\subsection{Electromagnetic Effects}

For noncontact excitation, free end of the beam in Oberst beam technique is excited with an electromagnetic exciter. Although the drawbacks of contacting type of excitation are eliminated by this way, there might be other undesirable effects that need to be avoided. In this section, the effect of positioning the free end of the beam into the exciter slot is investigated and how the undesirable effect can be minimized is described.
Noncontact excitation system used in this study is shown in Fig. 12. When the tip of the test specimen is almost at the bottom of the electromagnetic exciter slot (i.e., h is very small), the effective length of the clamped beam is reduced although the electromagnetic excitation is most effective. The effect of electromagnetic excitation on the measured results is investigated by varying the h value from $1 \mathrm{~mm}$ to $9 \mathrm{~mm}$.

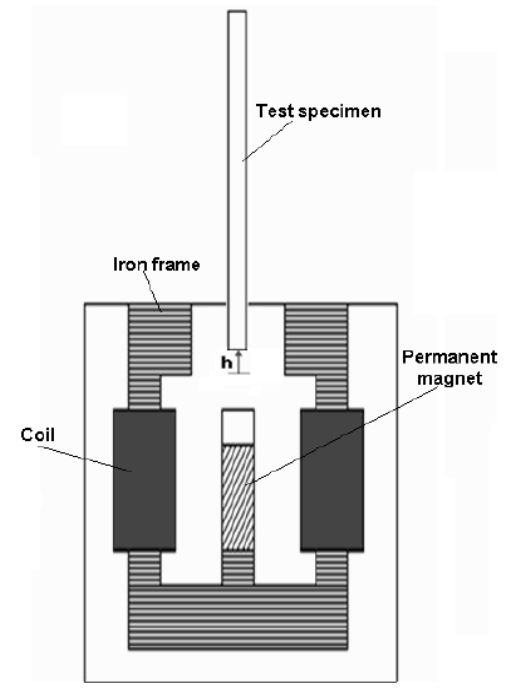

Figure 12. NONCONTACT EXCITATION SYSTEM.

Natural frequencies and estimated Young's modulus of a bare beam $(\mathrm{L}=220 \mathrm{~mm})$ that is exposed to different levels of magnetic field (for $\mathrm{h}=1 \mathrm{~mm}$ to $\mathrm{h}=9 \mathrm{~mm}$ ) are listed in Table 4 . The first mode of the beam (which is not used for the determination of material properties) is also included in Table 4.4. The first obvious thing is that the use the first mode cannot result in any consistent material properties. In fact, this is one of the reasons why ASTM E756 standard states that this mode should not be used for the determination of material properties.

The estimated Young's modulus, E, are plotted against the mode number for different gap value $\mathrm{h}$ in Fig. 12. It is also clearly seen here that the first mode is worse affected by the gap value. As the natural frequency increases, the effect of the gap decreases.

The results in Fig. 12 are plotted again in Fig. 13, but this time the data associated with the first mode are excluded so as to make the effects of $h$ on modes other than the first one. It is clear that all the modes are somewhat affected by the gap between the tip of the beam and the bottom of the exciter slot. These results indicate that the most reliable measurements are obtained when $\mathrm{h}$ is about $9 \mathrm{~mm}$ for the noncontact exciter used in this study. 
Table 4. NATURAL FREQUENCIES AND ESTIMATED YOUNG'S MODULUS OF A STEEL BARE BEAM (L= $220 \mathrm{~mm})$ THAT EXPOSED TO THE DIFFERENT LEVELS OF MAGNETIC FIELD (for $\mathrm{h}=1$ to $\mathrm{h}=9 \mathrm{~mm}$ ).

\begin{tabular}{|r|r|l|}
\hline \multicolumn{3}{|c|}{$\boldsymbol{h = 1} \mathbf{~} \boldsymbol{m}$} \\
\hline Mode & $\mathrm{f}[\mathrm{Hz}]$ & $\mathrm{E}\left[\mathrm{N} / \mathbf{m}^{2}\right]$ \\
\hline 1 & 37,8 & $1,01 \mathrm{E}+12$ \\
\hline 2 & 114,3 & $2,35 \mathrm{E}+11$ \\
\hline 3 & 301,5 & $2,08 \mathrm{E}+11$ \\
\hline 4 & 586,5 & $2,05 \mathrm{E}+11$ \\
\hline
\end{tabular}

\begin{tabular}{|r|r|r|}
\hline \multicolumn{3}{|c|}{$\boldsymbol{h}=\mathbf{2} \mathbf{~} \boldsymbol{m}$} \\
\hline Mode & $\mathrm{f}[\mathrm{Hz}]$ & $\mathrm{E}[\mathrm{N} / \mathrm{m} 2]$ \\
\hline 1 & 31,4 & $6,95 \mathrm{E}+11$ \\
\hline 2 & 110,9 & $2,21 \mathrm{E}+11$ \\
\hline 3 & 300 & $2,06 \mathrm{E}+11$ \\
\hline 4 & 585,5 & $2,05 \mathrm{E}+11$ \\
\hline
\end{tabular}

\begin{tabular}{|r|r|l|}
\hline \multicolumn{3}{|c|}{$\boldsymbol{h = 3} \mathbf{~ m m}$} \\
\hline Mode & $\mathrm{f}[\mathrm{Hz}]$ & $\mathrm{E}[\mathrm{N} / \mathrm{m} 2]$ \\
\hline 1 & 28 & $5,54 \mathrm{E}+11$ \\
\hline 2 & 109,5 & $2,16 \mathrm{E}+11$ \\
\hline 3 & 299,4 & $2,06 \mathrm{E}+11$ \\
\hline 4 & 585,1 & $2,04 \mathrm{E}+11$ \\
\hline
\end{tabular}

\begin{tabular}{|r|r|r|}
\hline \multicolumn{3}{|c|}{$\boldsymbol{h}=\mathbf{4} \mathbf{~} \boldsymbol{m}$} \\
\hline Mode & $\mathrm{f}[\mathrm{Hz}]$ & $\mathrm{E}[\mathrm{N} / \mathrm{m} 2]$ \\
\hline 1 & 24,5 & $4,24 \mathrm{E}+11$ \\
\hline 2 & 108,4 & $2,11 \mathrm{E}+11$ \\
\hline 3 & 298,9 & $2,05 \mathrm{E}+11$ \\
\hline 4 & 584,6 & $2,04 \mathrm{E}+11$ \\
\hline
\end{tabular}

\begin{tabular}{|r|r|r|}
\hline \multicolumn{3}{|c|}{$\boldsymbol{h = 5} \mathbf{~ m m}$} \\
\hline Mode & $\mathrm{f}[\mathrm{Hz}]$ & $\mathrm{E}[\mathrm{N} / \mathrm{m} 2]$ \\
\hline 1 & 22 & $3,42 \mathrm{E}+11$ \\
\hline 2 & 107,6 & $2,08 \mathrm{E}+11$ \\
\hline 3 & 298,5 & $2,04 \mathrm{E}+11$ \\
\hline 4 & 584,6 & $2,04 \mathrm{E}+11$ \\
\hline
\end{tabular}

\begin{tabular}{|r|r|l|}
\hline \multicolumn{3}{|c|}{$\boldsymbol{h = 6} \mathbf{m m}$} \\
\hline Mode & $\mathrm{f}[\mathrm{Hz}]$ & $\mathrm{E}[\mathrm{N} / \mathrm{m} 2]$ \\
\hline 1 & 20,6 & $3,01 \mathrm{E}+11$ \\
\hline 2 & 107,3 & $2,07 \mathrm{E}+11$ \\
\hline 3 & 298,4 & $2,04 \mathrm{E}+11$ \\
\hline 4 & 584,4 & $2,04 \mathrm{E}+11$ \\
\hline
\end{tabular}

\begin{tabular}{|r|r|l|}
\hline \multicolumn{3}{|c|}{$\boldsymbol{h}=\mathbf{7} \mathbf{~ m m}$} \\
\hline Mode & $\mathrm{f}[\mathrm{Hz}]$ & $\mathrm{E}[\mathrm{N} / \mathrm{m} 2]$ \\
\hline 1 & 19,4 & $2,65 \mathrm{E}+11$ \\
\hline 2 & 107 & $2,06 \mathrm{E}+11$ \\
\hline 3 & 298,4 & $2,04 \mathrm{E}+11$ \\
\hline 4 & 584,4 & $2,04 \mathrm{E}+11$ \\
\hline
\end{tabular}

\begin{tabular}{|r|r|r|}
\hline \multicolumn{3}{|c|}{$\boldsymbol{h}=\mathbf{8} \mathbf{~ m m}$} \\
\hline Mode & $\mathrm{f}[\mathrm{Hz}]$ & $\mathrm{E}[\mathrm{N} / \mathrm{m} 2]$ \\
\hline 1 & 18,8 & $2,48 \mathrm{E}+11$ \\
\hline 2 & 106,9 & $2,05 \mathrm{E}+11$ \\
\hline 3 & 298,3 & $2,04 \mathrm{E}+11$ \\
\hline 4 & 584,4 & $2,04 \mathrm{E}+11$ \\
\hline
\end{tabular}

\begin{tabular}{|r|r|r|}
\hline \multicolumn{3}{|c|}{$\boldsymbol{h}=\mathbf{9} \mathbf{m m}$} \\
\hline Mode & $\mathrm{f}[\mathrm{Hz}]$ & $\mathrm{E}[\mathrm{N} / \mathrm{m} 2]$ \\
\hline 1 & 18,1 & $2,32 \mathrm{E}+11$ \\
\hline 2 & 106,8 & $2,05 \mathrm{E}+11$ \\
\hline 3 & 298,1 & $2,04 \mathrm{E}+11$ \\
\hline 4 & 584,3 & $2,04 \mathrm{E}+11$ \\
\hline
\end{tabular}

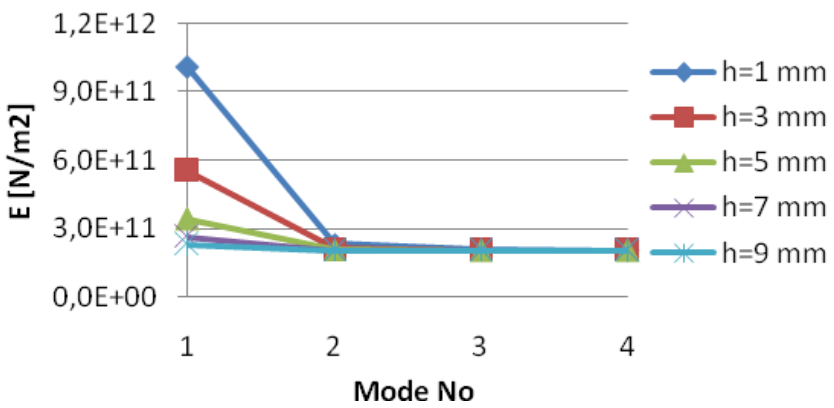

Figure 12. YOUNG'S MODULUS FOR VARIOUS LEVELS OF MAGNETIC FIELD (FOR VARIOUS h VALUES).

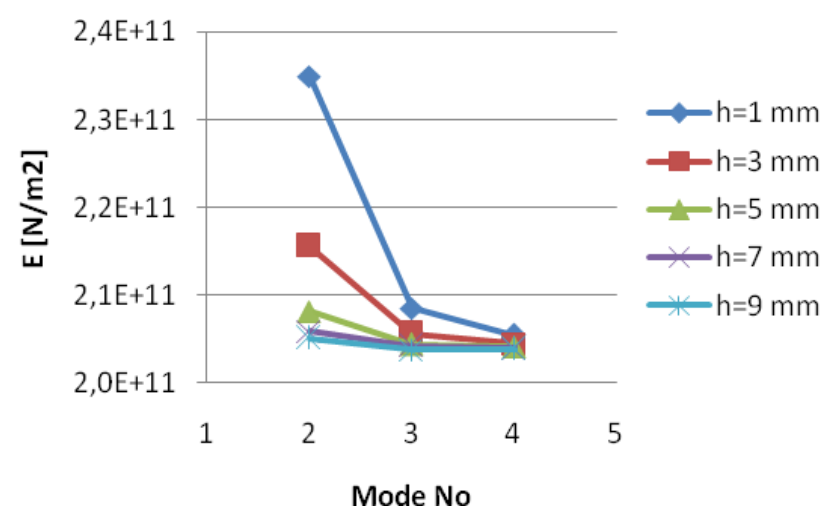

Figure 13. YOUNG'S MODULUS FOR VARIOUS LEVEL OF MAGNETIC FIELD (FOR VARIOUS h VALUES) EXCLUDING FIRST MODE.

Also, by conducting experiments on beams with various lengths, it is seen that the effect of the gap parameter changes according to beam length (see Fig. 14). This is as expected since the main effect of the gap parameter is to change the effective free length of the beam. In Fig. 14, the values of the estimated Young's modulus using the second natural frequencies are plotted for various beam lengths as a function of the gap parameter (again for $\mathrm{h}=1 \mathrm{~mm}$ to $\mathrm{h}=9 \mathrm{~mm}$ ). It is seen that as the $h$ value increases, the results converge to the same value of the Young's modulus. This also implies that the $h$ value must be kept as high as possible while keeping the excitation at acceptable levels.

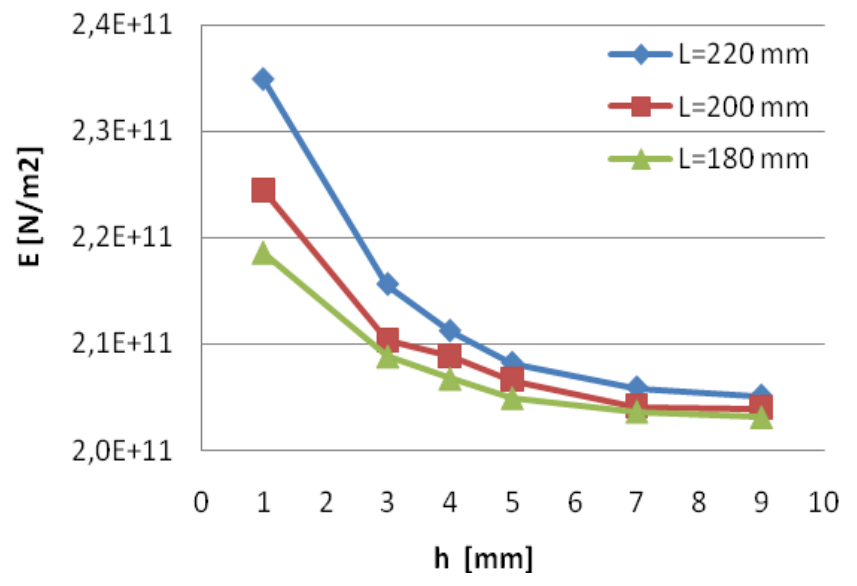

Figure 14. YOUNG'S MODULUS WITH RESPECT TO MAGNETIC FIELD FOR VARIOUS BEAM LENGTHS.

\subsection{Length of the Test Specimen}

It is obvious that longer specimens are more flexible than shorter ones. So, if more number of modes in the frequency range of interest are desired to be investigated, longer specimens should be selected. Similarly, if a few numbers of modes in the frequency range of interest are desired to be investigated, shorter specimen could be selected. Also, if there 
are some noise at some specific frequencies (for example at 50 $\mathrm{Hz}$ and its harmonics) and it is not possible to get rid of them, appropriate specimen length can be chosen so that the $50 \mathrm{~Hz}$ and its harmonics are away from natural frequencies. In section 3.3 it was also shown that as the beam length increases the effect of the gap increases.

\subsection{Preparation of Samples}

The geometric tolerances of the beam samples are very important in Oberst Beam Method (OBM). If the differences between the samples are high or the geometric properties are not identified accurately, the estimated material properties will not be reliable at all. Furthermore, how the composite beam is formed/glued is very important. Two measured FRFs are presented in Fig. 15 and Fig. 16 for two different composite beams. In the first case (Fig. 15), the beam is coated with a damping material. In the second case (Fig. 16), the beam is coated with the same damping material but there is an additional aluminum foil coating on it. Two damped beams, one of which had an additional aluminum foil coating, are shown in Fig. 17. As can be seen in Fig. 16, there are some local peaks around the second mode in the case of the sample with aluminum foil coating. It is believed that this is due to the aluminum foil not being cut or glued very precisely and it may cause some local modes associated with the aluminum foil itself. So, geometric properties as well as how the individual layers are joined together are also very important.

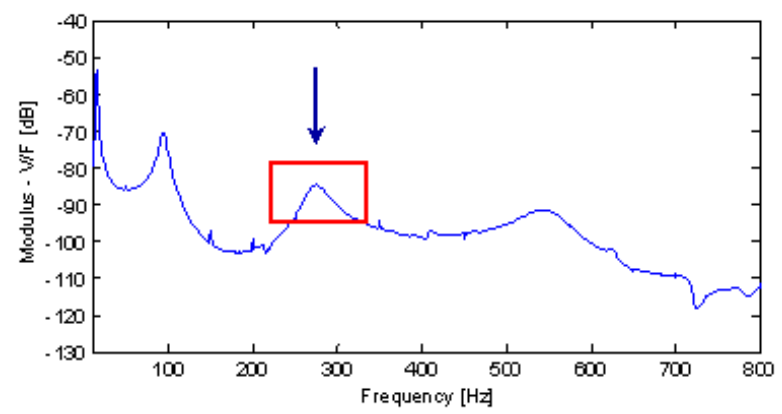

Figure 15. MEASURED FRF ON A DAMPING MATERIAL WITH NO ALUMINUM FOIL COATING.

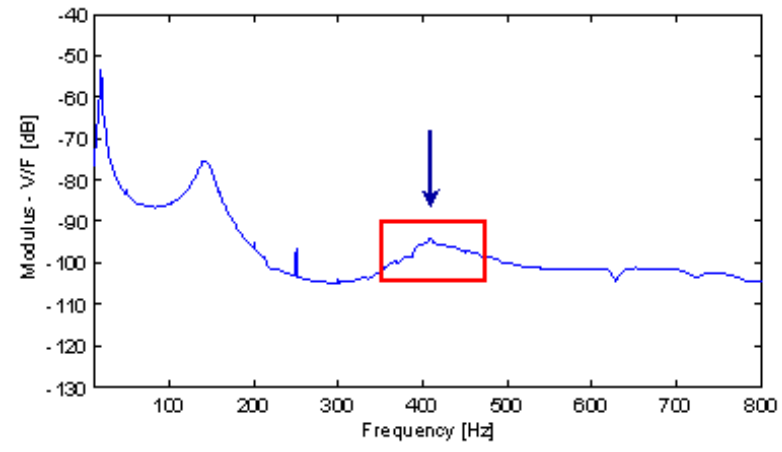

Figure 16. MEASURED FRF ON A DAMPING MATERIAL WITH ALUMINUM FOIL COATING.

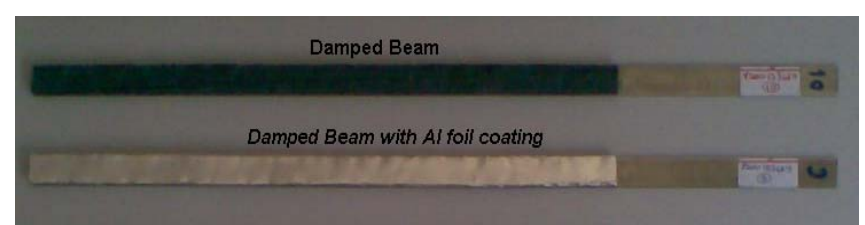

Figure 17. DAMPED BEAM AND DAMPED BEAM WITH ALUMINUM FOIL.

\section{CONCLUDING REMARKS}

In this paper, the effects of various parameters on measured data using an Oberst test rig are examined in an attempt to improve the accuracy of the estimated material properties. After setting up the Oberst test rig, repeatability measurements are performed and the main parameters affecting the quality of the measured data are determined. Then, extensive tests are performed in order to determine the effect of the amplitude of the excitation force, electromagnetic excitation, the length of the test specimen and the sample preparation.

Random and sine sweep excitations give nearly the same results provided that the sweep rate in sine testing is set properly. In both cases spectrum averaging should be performed in order to reduce the noise levels. Repeatability tests must be performed in Oberst Beam Method (OBM) in order to ensure reliable and repeatable measurements.

Sample preparation, geometric tolerances and joining/gluing the individual layers of the composite beam affects the results significantly. The effects of excitation amplitude should be investigated thoroughly before the final measurements are made. Low level of excitation may lead to noisy data while the high forcing levels can cause nonlinear effects.

Finally, it is found that positioning the tip of the beam into the electromagnetic exciter slot has huge effects on the results. As the electromagnetic effect is minimized, the results converge to the same value of the Young's modulus. This implies that the tip of the Oberst beam should be as far away as possible from the exciter slot while keeping the excitation at acceptable levels. It is also found that the electromagnetic effect depends on the beam length as this changes the effective free length of the beam.

\section{REFERENCES}

[1] Flint, J., 2003, “A Review of Theories on Constrained Layer Damping and Some Verification Measurements on Shim Material,” Proc. 21st Annual Brake Colloquium and Exhibition, Hollywood, Florida, USA.

[2] Oberst, H., 1952, "Über die Dämpfung der Biegeschwingungen Dünner Bleche Durch Fest Haftende Belage,” J. Acustica, 2(4), pp. 181-194.

[3] Ross, D., Ungar, E.E., and Kerwin Jr., E.M., 1959, "Damping of Plate Flexural Vibrations by Beams of 
Viscoelastic Laminate,” ASME, J. Strucrural Damping, pp. 48-88.

[4] Gross, B., 1953, Mathematical Structure of the Theories of Viscoelasticity, Herman, Paris.

[5] Edward, M., and Kerwin Jr., 1959, "Damping of Flexural Waves by Constrained Viscoelastic Layer,” J. Acoustical Society of America, 31, pp. 952-962.

[6] DiTaranto, R.A., 1965, "Theory of Vibratory Bending for Elastic and Viscoelastic Layered Finite-Length Beams," ASME, J. Applied Mechanics, 32, pp. 881-886.

[7] ASTM E756-05 standard, 2005, "Standard Test Method for Measuring Vibration-Damping Properties of Materials,” American Society for Testing and Materials.

[8] Wojtowicki, J. L., Jaouen, L., and Panneton, R., 2004, "New Approach for the Measurement of Damping Properties of Materials Using the Oberst Beam,” j. American Institute of Physics, 75 (8), pp. 2569-2574.

[9] SAE J1637 standard, 1993, "Laboratory Measurement of the Composite Vibration Damping Propeties of Materials on A Supporting Steel Bar,” SAE J1637 FEB93, SAE Recommended Practice.

[10] Hirabayashi, P., Rusch, P., McCaa, D., Saha, P., Rebandt, R., and et al., 1995., "Application of Noise Control and Heat Insulation Materials and Devices in the Automotive Industry,“ SAE International Proc. of the 1995 Noise and Vibration Conference, Traverse City, MI.

[11] Singh, R. V., and Pellny, M., 1998, "Lightweight, HighPerformance, Constrained-Layer Sound Dampers” Proc. International Congress and Exposition, Detroit, Michigan, USA.

[12] Chen, A. and Qian, Y., 1999, “Simulating Low Frequency NVH of Damped Automotive Body Panels Using Frequency Dependent Properties,” SAE International Proc. of the 1999 Noise and Vibration Conference, Traverse City, MI.

[13]Lewis, T., Jackson, P., and Nwankwo, O., 1999, “Design and Implementation of a Damping Material Measurement/Design System," SAE International Proc. Noise and Vibration Conference, Traverse City, MI, USA.

[14]Lilley, K. M., Fasse, M. J., and Weber, P. E., 2001, “A Comparison of NVH Treatments for Vehicle Floorpan Applications," SAE International Proc. Noise and Vibration Conference.

[15]Dobson, B. J., 1987, “A Straight -Line Technique for Extracting Modal Properties from FRF data”, J. Mech. Systems and Signal Proc., 1(1), pp. 29-40. 